\title{
A system dynamics approach for water resources management with focusing on domestic water demand
}

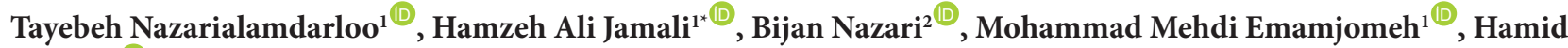 \\ $\operatorname{Karyab}^{1}$
}

${ }^{1}$ Environmental Health Department, Qazvin University of Medical Sciences, Qazvin, Iran

${ }^{2}$ Water Sciences and Engineering Department, Imam Khomeini International University, Qazvin, Iran

\footnotetext{
Abstract

Background: Due to the complexity and interdependence of water resources, the evaluation of the efficiency of water resources management is difficult. So, it is necessary to use effective modeling methods to study and recognize the feedback loops available in water resources systems. Regarding the importance of domestic water for the human health, the aim of this study was to develop a dynamic model with focusing on domestic water management.

Methods: This study was performed using a system dynamics approach. The strategies used in this study include population scenarios (ps), water use education scenarios (wu education), and agricultural water management scenarios (Agriwm).

Results: There was a significant relationship between education on water saving in domestic sector and water use per capita. In various scenarios of population growth, domestic water use was declined rapidly with education. According to the obtained results, under "ps3-wu education" scenario, lower population growth, and higher water use education, domestic water use will reach the minimum level, by 2041 . The results showed that the proposed scenarios can lead to $60 \%$ reduction in domestic water use.

Conclusion: With education strategy, water use per capita up to 2024 can reach the optimum level of 100 liters per person per day. However, without education even by 2041, this goal is unattainable. So, sustainable goals can be achieved by adopting education strategy. The developed systematic model can be applied in various conditions. In each study area, the regional water and population data should be provided.

Keywords: Water resources, Population growth, System dynamics, Water use education, Agricultural water management scenarios (Agriwm)

Citation: Nazarialamdarloo T, Jamali HA, Nazari B, Emamjomeh MM, Karyab H. A system dynamics approach for water resources management with focusing on domestic water demand. Environmental Health Engineering and Management Journal 2020; 7(4): 229-235. doi: 10.34172/EHEM.2020.27.
}

\section{Introduction}

Population growth and urbanization have increased the need for domestic water, food safety, and environmental protection, agricultural, industrial, and commercial water. Furthermore, safe drinking water is one of the necessities to sustain life, and a satisfactory (adequate, safe, and accessible) supply of water must be available for all people $(1,2)$. According to the new global attitude, water is a socioeconomic commodity and it is considered as the primary and vital need of every human being (3). Although, water is a renewable resource, but the amount and speed of this process is verylow, slow and long. With regards to the rapid population growth, raising the level of public health and welfare, water resources per capita are declining. Given the current situation in third world countries and the rapid growth of population and urbanization, increased water use in developed countries, and political tensions around the world are limiting factors for access to adequate water resources (4). So, water scarcity and lack of adequate and proper water resources in different parts of the world has been warned by various international organizations such as the World Bank (5) and the World Health Organization (6). One of the ways to control water crisis and droughts is proper water management with regard to water demand management. Water demand management refers to activities that help reduce water demand and water use efficiency and prevent contamination or destruction of resources. In water resource management should pay more attention to water demand management. Water demand management is a difficult variable to influence due to the pressure of uncontrolled factors, such as weather conditions, population growth, and urbanization 
(7). Therefore, it is difficult to assess the effectiveness of management decisions in water resources management due to the complexity and interconnection of water resources systems. For this reason, using strong modeling techniques for the study and identifying feedback loops in water resources systems are necessary.

System dynamics (SD) is one of the most powerful management tools used in recent years to simulate complex water resources. There are some previous studies that tried to analyze water systems in different ways. An SD approach used for modeling the dynamics of groundwater discharge under different economical and climate change scenarios (8) and the evaluation of water scarcity using an SD approach (9), showed that the proposed models can be used to assess the long-term effects of water policies and strategies, especially, policies that reduce the water demand. The SD approach can be applied to enhance integrated water resource planning (10). So this method can identify necessary guidelines for economically sustainable water supply. Also, the combination of SD and optimization method can be applied for supporting sustainable water resources. The results of a study on water resources planning in Zhengzhou City, China (11) showed that the combination of optimization method and dynamic models can help water resources managers in cities which are facing water shortages. Similar results were achieved in the integrated water resources dynamic modeling of the Saskatchewan River basin in western Canada (12). Other capabilities of the SD approach are comprehensive management of surface water and groundwater by integrating hydrological, social, economic, and political data (13), the evaluation of the reservoir behavior under changing climatic conditions (14), and the exploration of the limitations and opportunities to achieve safe drinking water (15).

In a comprehensive study on domestic water management using SD approach, it was revealed that domestic water resources have been facing significant pressure from population growth, urbanization, and climate changes (16). In this research, the systematic water management model was proposed to simulate the dynamic interactions between urban water demands and society, economy, climate, and water conservation. Also, SD approach was applied to reflect the intrinsic relationship between water demand and macroeconomic environment using municipal water demand forecasts in a fast-growing urban region (17). In another study in Iran, a system dynamic model was developed to simulate the effectiveness of sectoral, municipal, industrial, agricultural water resources management and environmental protection policies. The results indicated that system dynamic method has a high capability for multi-sectoral water management analysis (18).

Iran is currently facing a severe water crisis, and due to the constant water resources, population growth, and not paying enough attention to the management of water resources, if not adopted appropriate and timely water resources management policies in both supply and demand, intensification of unfavorable water resources status in the country and the impact of security and economic indicators will be inevitable. Regarding the importance of domestic water in human health, the overall aim of the present study was to evaluate the water resources management focusing on domestic water demand management solutions.

System dynamics (SD) modeling is a technique that describes how a system operates. This method can be used to determine changes resulting from a specific action and strategy. Developed models in system dynamic approach have a global application. The developed model structure can be used in various regions but the model accuracy can be tested in a specific region as a case study. In this research, Qazvin province water and population data $(19,20)$ were used for model evaluation. Five general steps used in applying the SD modeling process include 1) Defining the problem; 2) Description of the system; 3) Model development; 4) Model validation; 5) Using the model to analyze policies (21). VENSIM which is a common tool for dynamic modeling and an objectoriented simulation environment based on the feedback, was used for modeling $(22,23)$.

\section{Materials and Methods \\ Defining the problem}

The problem definition step includes a statement of the problem in the system that the existing entity is seeking to resolve (24). Water is one of the most important challenges facing humanity this century, which can be the source of many positive or negative changes at the national and international levels. Iran is one of the countries that have been faced with water tension and crisis. It has led to a sharp drop in groundwater and surface water levels, reduced agricultural production and increased cost of agricultural production process, declined wildlife populations, especially aquatic population, reduced biodiversity in plants and animals, and challenging water resources management. In this very critical condition, it is inevitable to apply regulatory policies and change and modify the consumption pattern. One of the ways to control water crisis and droughts is proper water management with regard to water demand management, that help reduce water demand and water use efficiency, as well as preventing contamination or destruction of resources. Regarding the importance of domestic water use in the human health, this study was designed to provide solutions for domestic water demand management.

System description

The first step in this phase is determination of the system boundary. At this step, one should specifically focus on the boundary of the system in which the problematic structure is formed. In other words, by explaining subvariables (variables affecting the reference variable), one 
can find a structure of the model from which real behavior of system can be derived. General concept of the model is presented in Figure 1. In this study, by examining the problems of water resources management with focusing on domestic water demand management, variables affecting the domestic water demand management at different levels were categorized based on the previous studies, then, variables affecting domestic water demand management were expressed.

\section{Model development}

The causal-effect loops diagram of the SD modeling represents a comprehensive understanding of the system structure, including positive and negative relationships between variables. These diagrams are a good tool for drawing the feedback structure of systems. The causeeffect loops diagram of the water resources management is presented in Figure 2.

Stock and flow together with feedback are two essential concepts of SD analysis. In fact, stock and flow are developed to indicate accumulations and depletions in response to flows within the system. The stock and flow diagram of the water resources management is presented in Figure 3.

\section{Model validation}

SD models are always assessed by their particular structures (25). Before using the model in scenario analysis, it is essential to validate the model structure and behavior $(26,27)$. In this study, dimensional accuracy test and model behavior tests were used to validate the model,

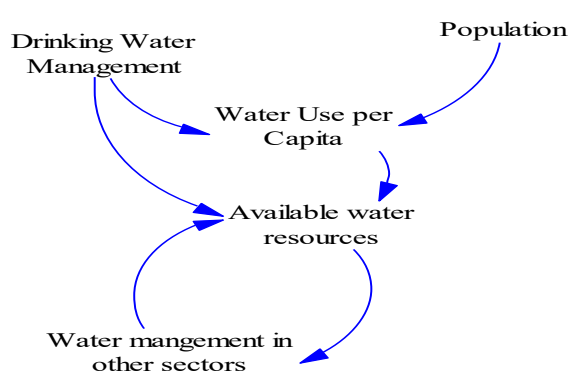

Figure 1. General conceptual structure of the model.

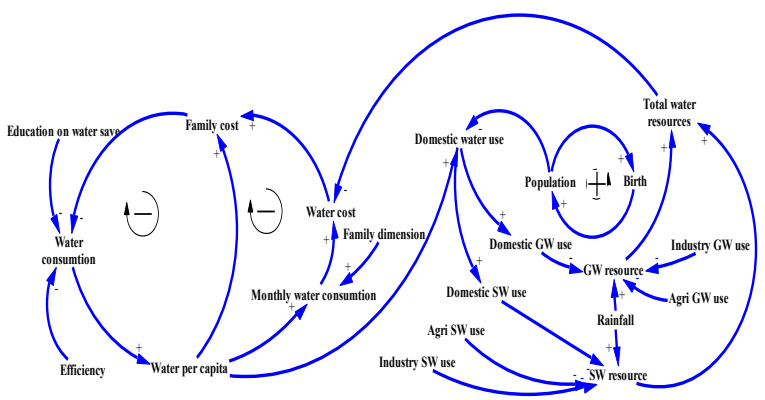

Figure 2. Causal-effect loops diagram of the water management.

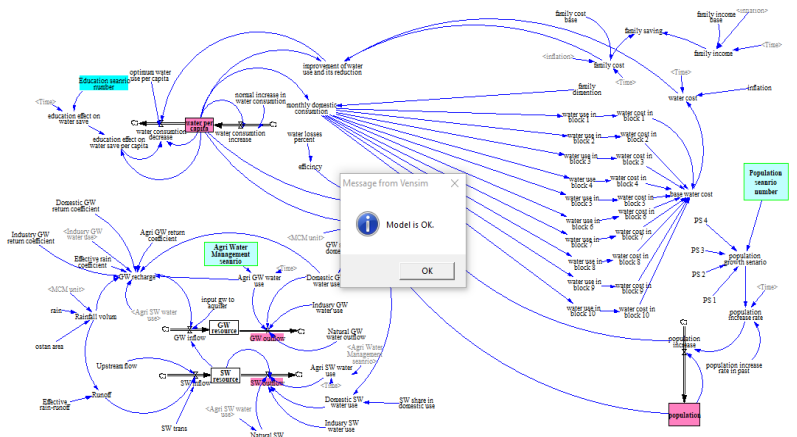

Figure 3. Structure test of the developed model, stock-flow diagram .

which are described below.

Dimensional accuracy test is one of the basic tests that should be considered from the beginning of the modeling process. In this test, the measurement units for each variable produced in the model should be examined. In the model development process, the units' compatibility to match the units to each other were investigated. Figure 3 shows the results of investigation of the dimensional accuracy of the final model.

Also, behavior test examines the model outputs. The data generated by the model should be compared with available data from field studies or system historical data. The conventional relative error (RE) and Root mean squared error (RMSE) indices were used to test the system behavior. The RMSE and RE are defined as follows (28):

$$
\begin{aligned}
& R M S E=\sqrt{\frac{\sum_{\mathrm{i}=1}^{\mathrm{n}}\left(\mathrm{P}_{i}-\mathrm{O}_{i}\right)^{2}}{\mathrm{n}}} \\
& R E=\frac{\left(\mathrm{P}_{i}-\mathrm{O}_{i}\right)}{\mathrm{O}_{i}} \times 100 \%
\end{aligned}
$$

Where $P_{i}$ and $O_{i}$ are the predicted and observed values, respectively, and $n$ is the total number of data.

The minimum value of RE and RMSE is zero. One of the important parameters in water simulation models is the groundwater level. Therefore, this parameter is considered as a reference parameter to evaluate the model performance.

\section{Analyzed strategies}

In this study, to assess domestic water demand management solutions, three following scenarios were utilized:

- Population scenarios (based on the Iran National Statistics scenarios in population projection)

- Water use education scenarios

- Agricultural water management scenarios

In order to determine the impact of existing system conditions and different scenarios in the future years, the model was implemented for 2006-2041. Studied scenarios and levels applied to the relevant scenarios for water resources management are presented in Table 1. 
Table 1. Studied population, education and water management strategies

\begin{tabular}{lll}
\hline Scenario category & Scenario name & Scenario details \\
\hline $\begin{array}{lll}\text { Population growth scenarios } \\
\text { (Based on the Iran National Statistics scenarios in population } \\
\text { projection) }\end{array}$ & ps1 & Current trend of population growth \\
& ps3 & Low population growth rate \\
Water use education scenarios & ps4 & Very Low population growth rate \\
& wu education & Education on water saving in domestic sector \\
Agricultural water management scenarios & No education & No education on water saving in domestic sector \\
\hline
\end{tabular}

${ }^{*}$ Total studied scenarios are 16 (4 population scenarios, 2 education scenarios, 2 water management scenarios).

\section{Results}

\section{Model behavior test results}

As discussed in the previous sections, model should be evaluated before application. Hence, the model results should be compared with available historical data. Figure 4 shows the simulated and observed groundwater table in Qazvin province as a case study.

Model evolution showed that the RE index of the developed model was $-0.14 \%$ and RMSE index was 45.08 $\mathrm{m}$ (groundwater level was $1190 \mathrm{~m}$ ). These values indicate that the model has a good accuracy, therefore, it can be used for analyzing scenarios in the study area.

\section{Population projection}

Population projections are trying to show how the population will change in the future. These projections are an important input to analysis the impact of populations on this planet and humanity's future well-being (29). In Iran, population projection is done based on the Iran National Statistics scenarios in population projection, which has four standard scenarios and is described in Table 1. In this study, population projection was based on these four scenarios. Figure 5 shows estimates and probabilistic projections of the total population for Iran up to 2041 (compared to its population in 2006). The country's population is expected to reach 1.4 million persons at the lowest level in 2041 and about 1.6 million people at the highest level.

\section{Water use per capita}

Investigation of the effect of education on water use per capita indicated that there is a significant relationship between education and water saving in domestic sector. In other words, as the awareness and knowledge about optimal water use increase, water use per capita will decrease. As shown in Figure 6, by providing education between 2019 and 2024, the water use per capita from its current level (270 L/day) will reach its optimal rate $(100 \mathrm{~L} /$ day). After reaching $100 \mathrm{~L} /$ day, the system found a goalseeking behavior. The water use per capita fluctuates around this optimal rate, $100 \mathrm{~L} /$ day, up to 2041.

\section{Discussion \\ Domestic water use}

In various scenarios of population growth while providing education, domestic water use was declined rapidly, and the system found a goal-seeking behavior due to the water cost feedback and water use education (Figure 7). For example, in Qazvin province, as a case study, between 2019 and 2024, the domestic water use from its current level (135.56 MCM/year) will reach its optimal rate (54.660.2 MCM/year in various population growth scenarios). But without water use education, domestic water use has been decreased with a mild slope.

This is an interesting point that in 2041, different population and education scenarios have tended to a certain value. This shows that on a long-term horizon, population is an important determinant factor in the total

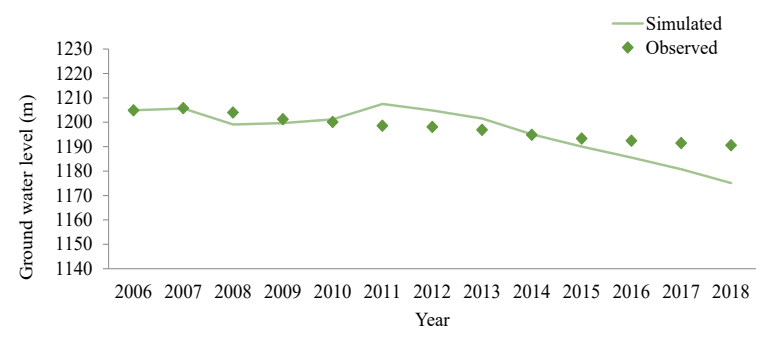

Figure 4. Model behavior test in the simulation of groundwater level.

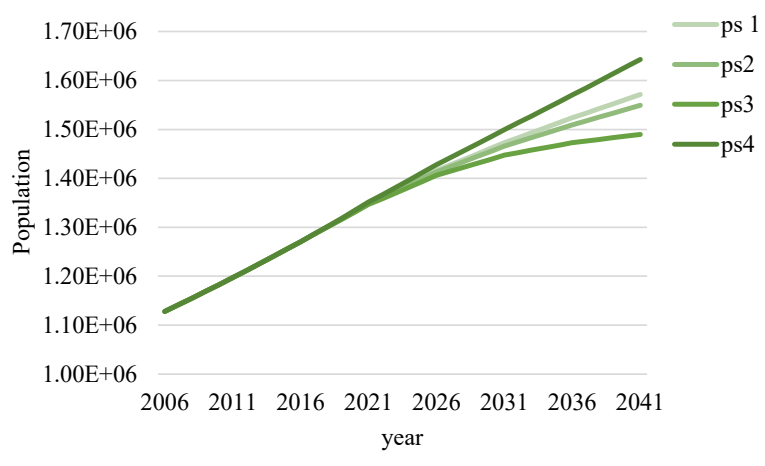

Figure 5. Population projection in four population growth scenarios. 


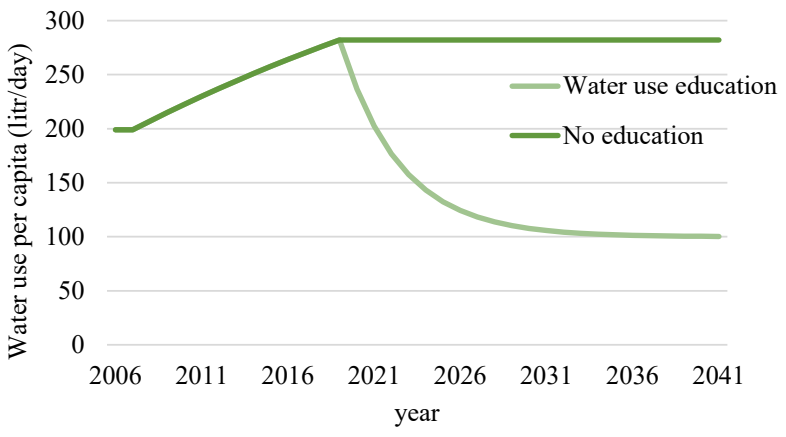

Figure 6. Water use per capita in the education scenarios.

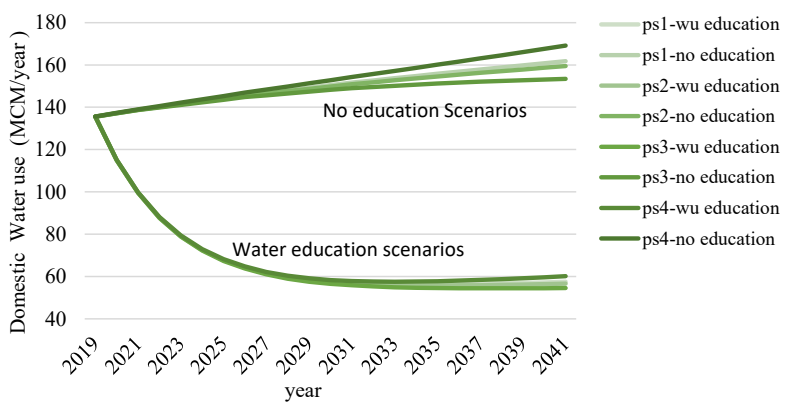

Figure 7. Domestic water use in the studied scenarios.

domestic water use. Water use management can reduce to some extent water use per capita, and further reduction may not be hygienically possible. Therefore, in water scarcity adaptation projects, particular attention should be paid to the population factor. The predicted domestic water use in different scenarios in 2041 is presented in Figure 8.

\section{Groundwater use}

Figure 9 illustrates the effect of population scenarios under water use education, and the agricultural scenario was also considered. Among the population scenarios, the most likely scenario (ps1 scenario) was examined.

It can be seen that if there was an education on the optimal water use in domestic sector, water use per capita up to 2024 can reach 100 liters per person per day. However, without education even by 2041, this goal is unattainable. This illustrates the importance and necessity of education and culture. Goal-seeking behavior in Figure 7 shows that with water use education, water use per capita is reduced. This reduction in water use leads to a decrease in the share of household water costs. By reducing the share of water cost, water use increases, but with re-education, water use decreases to the desired level (Figure 2). The goal pattern in system dynamics studies is one of the most interesting results.

The "ps3-wu education" scenario is the best one, which shows that if population growth decrease and water use education is also provided, the lowest domestic water use will be achieved up to 2041. But under "ps4-no education" scenario, if population growth increases and water use education is not provided, the highest domestic water use will be achieved up to 2041. These results show that one of the reasons for extravagance or non-compliance with optimal water consumption patterns can be due to the lack of sufficient education about these patterns. Due to the imbalance between supply and the growing national demand for water, the need for water efficiency is important. However, water demand management requires knowledge of how water is consumed. Water saving can be achieved through direct and indirect education. Given that women in the family manage water consumption, raising their level of knowledge and awareness related to the modification of consumption patterns will be very effective, and it can correct short-term effects on both the reduction of family water use and the water consumption pattern used by other family members. Other researchers have also reported that water consumption in households that are aware about water consumption is significantly lower than that in households with less concern and awareness of water consumption (30). The low literacy of households has a negative effect on water consumption. In other words, by increasing the level of awareness and literacy of households through the necessary training, it is possible to increase water saving. However, urban water consumption has a lower percentage compared to agricultural water consumption, but given the high costs of domestic water supply, purification, transfer,

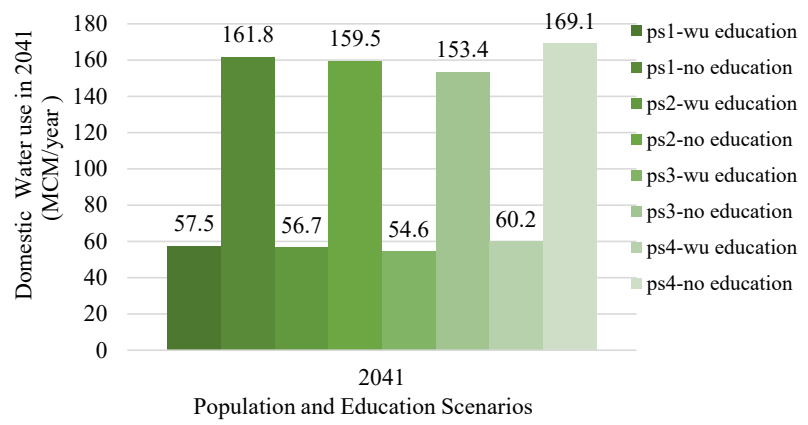

Figure 8. Domestic water use in the studied scenarios (2041).

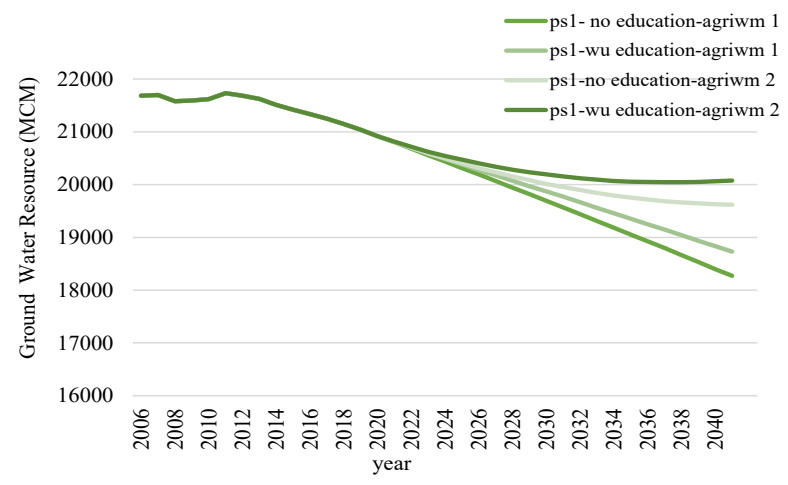

Figure 9. Groundwater use in the studied scenarios. 
and distribution, water saving in this section can have significant benefits.

As mentioned earlier, although providing education can have a significant effect on reducing domestic water use and water use per capita, but when these effects are considered for the region's water resources, optimal agricultural water use should also be considered. Agricultural water use in the region is very high and has a significant share in total groundwater use. If it is not considered and does not being paid attention, precise information on groundwater consumption cannot be provided. Figure 9 shows that groundwater has declined dramatically due to the irregular water withdrawal. If serious actions are not taken to reduce water use, especially in the main water-consuming sector (agriculture), domestic water management alone will not solve the water crisis in the region. The results show that agricultural water management will play a crucial role in improving groundwater status. Water use education strategy can help achieve groundwater sustainability.

\section{Conclusion}

Water scarcity challenge is a serious problem in the world. This challenge can be intensified with climate change (31). So, the study of water scarcity adaptation strategies is a necessity for humanity. Investigation of the effect of water use education on water use per capita indicated that there is a significant relationship between education on water saving in domestic sector and water use per capita. In other words, as awareness and knowledge about optimal water use increase, water use per capita will decrease. One of the reasons for the extravagance or non-observance of the optimal water use patterns can be due to the lack of sufficient knowledge about the above-mentioned patterns. With regards to the lack of balance between supply and demands for the national water growth, the need for productivity in water use is significant. Nevertheless, water demand managing requires knowledge about how to use water. If water use education strategy is taken, the optimal water use in domestic sector can be achieved. With this strategy, water use per capita up to 2024 can reach 100 liters per person per day. However, without education even by 2041, this goal is unattainable. This illustrates the importance and necessity of education and culture. In various scenarios of population growth, by providing education, domestic water use has declined rapidly, and the system found a goal-seeking behavior due to the water cost feedback and water use education. In the period between 2019 and 2024, the domestic water use from its current level (135.56 MCM/year) will reach its optimal rate (54.6-60.2 MCM/year in various population growth scenarios). This improvement is about $60 \%$ reduction in domestic water use. This shows that on a long-term horizon, population is an important determinant factor in the total domestic water use. Similar studies with system dynamics approach in China have shown that the water demand is sensitive to the changes in population and per capita demand. By implementing integrated Water Resources Management measures and improving water conservation willingness, water demand could be reduced by $17.5 \%$ (16). The results of the present study showed that there is more improvement potential in the study area (Qazvin). One of the main reasons for this improvement potential is high water use rate in the current conditions.

Although providing education can have a significant effect on reducing the amount of domestic water use and water use per capita, in the study area, the optimum agricultural water use should also be considered. Regarding the high importance of domestic water management in the society health and well-being, education on water use in this issue, can be proposed as an important priority in water resources management. However, the impacts of policies proposed by environment, water, and agriculture sectors should be analyzed in a systematic view, and crosssectoral coordination is an essential key to success $(17,18)$.

Finally, the developed model in the present study can be used in various regions for water management strategies analysis. In each study area, the regional data such as hydrological data and population data should be provided.

\section{Acknowledgments}

The authors would like to gratitude the Ministry of Energy and Water Resources Management Authorities, for providing required data to conduct and complete this study.

\section{Ethical issues}

The authors certify that all data collected during the study are presented in this manuscript, and no data from the study has been or will be published separately. The research was approved by the Ethics Committee of Qazvin University of Medical Sciences (Ethical code: IR.QUMS. REC.1397.301).

\section{Competing interests}

The authors declare that they have no competing interests.

\section{Authors' contributions}

All authors participated in the study design, literature search, writing the manuscript, and data collection, analysis, and interpretation. All authors critically reviewed, refined, and approved the manuscript.

\section{References}

1. Pourakbar M, Mosaferi M, Lak S. Assessment of water supply system and water quality of Lighvan village using water safety plan. Environ Health Eng Manag 2015; 2(4): 187-92.

2. Sobhanardakani S, Taghavi L, Shahmoradi B, Jahangard A. Groundwater quality assessment using the water quality pollution indices in Toyserkan Plain. Environ Health Eng Manag 2017; 4(1): 21-7.

3. Nazari B, Liaghat A, Akbari MR, Keshavarz M. Irrigation water management in Iran: implications for water use 
efficiency improvement. Agric Water Manag 2018; 208: 7-18. doi: 10.1016/j.agwat.2018.06.003.

4. Connor R. The United Nations World Water Development Report 2015: Water for a Sustainable World (Vol. 1). Paris: UNESCO; 2015.

5. Wijnen M, Augeard B, Hiller B, Ward C, Huntjens P. Managing the Invisible: Understanding and Improving Groundwater Governance. Washington, DC: World Bank; 2012.

6. Babazade H, Saraei Tabrizi M. Water crisis control by considering water demand management and risk management. First International Congress on Water Crisis 2007 Mar 10-12; Zabol: Zabol University; 2007.

7. Elmahdi A, Malano H, Etchells T, Khan S. December. System dynamics optimisation approach to irrigation demand management. MODSIM 2005 International Congress on Modelling and Simulation; 2005 Dec; Melbourne, Australia: Modelling and Simulation Society of Australia; 2005. and New Zealand; 2005. p. 196-202.

8. Balali H, Viaggi D. Applying a system dynamics approach for modeling groundwater dynamics to depletion under different economical and climate change scenarios. Water 2017; 7(10): 5258-71. doi: 10.3390/w7105258.

9. Armenia S, Carvalho H, Ferreira franco E, Medaglia Carlo M, Nonino F, Pompei A. Understanding the root causes of water scarcity through System Dynamics: the Italian case of the Bracciano Lake.Cocreating responsible futures in the digital age. exploring new paths towards economic, social and environmental Sustainability 2018; 79-83.

10. Gastelum JR, Krishnamurthy G, Ochoa N, Sibbett S, Armstrong M, Kalaria P. The use of system dynamics model to enhance integrated resources planning implementation. Water Resour Manag 2018; 32(7): 2247-60. doi: 10.1007/ s11269-018-1926-4

11. Li Z, Li C, Wang X, Peng C, Cai Y, Huang W. A hybrid system dynamics and optimization approach for supporting sustainable water resources planning in Zhengzhou city, China. J Hydrol 2018; 556: 50-60. doi: 10.1016/j. jhydrol.2017.11.007.

12. Hassanzadeh E, Elshorbagy A, Wheater H, Gober P. Managing water in complex systems: an integrated water resources model for Saskatchewan, Canada. Environ Model Softw 2014; 58: 12-26. doi: 10.1016/j.envsoft.2014.03.015.

13. Sehlke G, Jacobson J. System dynamics modeling of transboundary systems: the bear river basin model. Ground Water 2005; 43(5): 722-30. doi: 10.1111/j.17456584.2005.00065.x.

14. Stojkovic, M, Simonovic SP. System dynamics approach for assessing the behaviour of the Lim Reservoir system (Serbia) under changing climate conditions. Water 2019; 11(8): 1620. doi: 10.3390/w11081620.

15. Rodriguez G. Barriers and Opportunities to Achieving Safe Drinking Water in Bangladesh: A System Dynamics Approach [dissertation]. Michigan: University of Michigan; 2018.

16. Wei T, Lou I, Yang Z, Li Y. A system dynamics urban water management model for Macau, China. J Environ Sci 2016; 50: 117-26. doi: 10.1016/j.jes.2016.06.034.

17. Qi C, Chang NB. System dynamics modeling for municipal water demand estimation in an urban region under uncertain economic impacts. J Environ Manage 2011; 92(6): 1628-41. doi: 10.1016/j.jenvman.2011.01.020.

18. Ravar Z, Zahraie B, Sharifinejad A, Gozini H, Jafari S. System dynamics modeling for assessment of waterfood-energy resources security and nexus in Gavkhuni basin in Iran. Ecol Indic 2020; 108: 105682. doi: 10.1016/j. ecolind.2019.105682.

19. Babaee S, Mousavi Z, Masoumi Z, Malekshah AH, Roostaei M, Aflaki M. Land subsidence from interferometric SAR and groundwater patterns in the Qazvin plain, Iran. International Journal of Remote Sensing 2020; 41(12): 4780-98. doi: 10.1080/01431161.2020.1724345.

20. Mehrazar A, Massah Bavani AR, Gohari A, Mashal M, Rahimikhoob H. Adaptation of water resources system to water scarcity and climate change in the suburb area of megacities. European Water Resources Association 2020; 34(12): 3855-77. doi: 10.1007/s11269-020-02648-8 .

21. Sterman J. System Dynamics: Systems Thinking and Modeling for a Complex World [dissertation]. Cambridge, MA: MIT Sloan School of Management; 2002.

22. Ventana Systems. User Guide - Vensim Introduction \& Tutorials. [cited 2019 Dec 10] Available from: https://www. vensim.com/documentation

23. Gohari A, Mirchi A, Madani K. System dynamics evaluation of climate change adaptation strategies for water resources management in central Iran. Water Resour Manag 2017; 31(5): 1413-34. doi: 10.1007/s11269-017-1575-z.

24. Goodman M. Everyone's Problem to Solve: Systems Thinking Cross-Functionally. The Systems Thinker Newsletter 2006; 17(5): 5-8.

25. Winz I, Brierley G, Trowsdale $S$. The use of system dynamics simulation in water resources management. Water Resour Manag 2009; 23(7): 1301-23. doi: 10.1007/s11269-0089328-7.

26. Barlas Y. Formal aspects of model validity and validation in system dynamics. Syst Dyn Rev 1996; 12(3): 183-210. doi: $\quad 10.1002 /($ sici)1099-1727(199623)12:3<183::aidsdr103>3.0.co;2-4.

27. Senge PM, Forrester JW. Tests for building confidence in system dynamics models. System dynamics, TIMS studies in management sciences. 1980; 14: 209-28.

28. Zacharias S, Heatwole CD, Coakley CW. Robust quantitative techniques for validating pesticide transport models. Trans ASAE 1996; 39(1): 47-54. doi: 10.13031/2013.27479.

29. Kaneda T, Bremner J. Understanding population projections: assumptions behind the numbers. [cited 2020 Feb 12] Available from: https://www.prb.org/unitednations-population-projections/

30. Willis RM, Stewart RA, Panuwatwanich K, Williams PR, Hollingsworth AL. Quantifying the influence of environmental and water conservation attitudes on household end use water consumption. J Environ Manage 2011;92(8): 1996-2009. doi: 10.1016/j.jenvman.2011.03.023.

31. Islam SM, Karim Z. World's demand for food and water: the consequences of climate change. [cited 2020 Dec] Available from:https://www.intechopen.com/books/desalinationchallenges-and-opportunities/world-s-demand-for-foodand-water-the-consequences-of-climate-change. doi: 10.5772/intechopen.85919. 